\title{
Dynamic analysis of soft hang-off riser in deep water, coupling the vibration of lateral and longitudinal directions
}

\author{
Liangjie Mao, Song Zeng and Qingyou Liu* \\ State Key Laboratory of Oil and Gas Reservoir Geology and Exploitation, Southwest Petroleum University, Sichuan, Chengdu 610500, China
}

\begin{abstract}
A dynamic analysis model of soft hang-off riser in deep water is developed to analyse the mechanical behaviour of a drilling riser. In this model, the riser is suspended by the tensioner at one end and is free at the other end. The movement of the riser can be considered as a process coupling the vibration of lateral and longitudinal directions. The model is studied using finite element method and verified by the results of ABAQUS and a similar experiment. The riser deformation, bending moment and longitudinal vibration in a well from the South China Sea are analysed and influences of lower marine riser package weight, evacuation and current velocities, desired track of the drilling platform, and length of the hang-off drilling riser on drilling riser deformation are discussed. The results are of significant importance for the practical operation of soft hang-off drilling riser during evacuation.
\end{abstract}

Keywords: Deep water, drilling riser, dynamic analysis, soft hang-off.

DRILLING risers, which are the connecting channels for the drilling platform and subsea blowout preventer (BOP) system, play an important role in deep-water drilling. However, drilling risers may be easily fractured due to ocean environment load. During an approaching typhoon, the drilling riser with lower marine riser package (LMRP) may be disconnected from the BOP, whereas the drilling platform with a suspended drilling riser must be evacuated to avoid the typhoon.

The force of drilling risers is highly complex under soft hang-off conditions. The ocean environment may affect the drilling risers. The platform may also influence the riser as it moves in the sea water. The included angle between the desired track and load direction induced by the ocean environment may considerably influence the force of the drilling risers. The risers may be destroyed when the bending moment surpasses the material strength in theory, thereby triggering accidents and enormous economic losses. Moreover, numerous accidents have been caused by the fracture of drilling risers during evacuation in the South China Sea ${ }^{1}$.

\footnotetext{
*For correspondence. (e-mail: liuqy66@aliyun.com)
}

Several researchers have focused on the mechanical analysis of drilling risers. Mao et $a l^{2}$ established a deepwater mechanical behaviour analysis model of drilling risers, considering an actual riser string configuration. Fan et $a l .^{3}$ established a hang-off riser model to analyse the influence of internal solitary wave on the risers. The results showed that attention should be paid to the impact of LMRP on other equipment on the seabed. Steddum ${ }^{4}$ discussed the response of a disconnected riser hanging on a drifting vessel, with particular emphasis on the response of the shear loads to the vessel. Sheng et al. ${ }^{5}$ summarized the related experience of China National Offshore Oil Corporation (CNOOC) on responding to severe weather in a hang-off mode and indicated that a contingency plan for a hang-off riser to resist severe weather is feasible. $\mathrm{Wu}$ et al. ${ }^{6}$ proposed a dynamical model for studying the dynamic response of the hard hang-off of a riser to evacuate with HYSY 981 drilling platform. A model for a hang-off riser was developed to calculate the operation envelope of the hang-off riser during severe weather ${ }^{7}$. Wang et al. ${ }^{8}$ identified influencing factors with respect to technical and commercial considerations that affect the selection of a hang-off riser system and established selection criteria for each influencing factor, along with the comparison of relative merits of each type of hang-off riser system. Ambrose et al. ${ }^{9}$ studied the soft hang-off riser models in ultra-deep water. They discussed the feasibility of the soft hang-off method and compared the characteristics of the hang-off riser by analysing a deepwater drilling riser during installation. Long et al. ${ }^{10}$ found that the response of the riser increased with axial storm. Dai et al. ${ }^{11}$ presented the effective tension of a drilling riser under operability and hang-off conditions. Yasukawa et al. $^{12}$ studied the limiting wave height of a deepwater hang-off riser. They discussed the influences of internal fluid mass on the riser and the associated fluid friction on the limiting wave height. Burgdorf $\mathrm{Jr}^{13}$ evaluated the axial and lateral modal superpositions for a 3D riser, showing that when the loads are close to the peak loads the resonance of riser will occur. A mechanical analysis model of deep water by ABAQUS was developed for the deep-water riser considering grounding risk; it demonstrates that the shape of the riser after grounding seabed is catenary ${ }^{14}$. 


\section{RESEARCH ARTICLES}

However, dynamic mechanical behaviour analysis model for drilling risers under soft hang-off conditions, coupling the vibration of lateral and longitudinal directions, is rare. The present study is aimed at analysing the dynamic mechanical behaviour of riser under soft hangoff conditions. A dynamic model for a riser under soft hang-off conditions is developed and analysed using finite element method (FEM). Then the model is verified by the results of ABAQUS and a similar experiment. The influences of LMRP weight, evacuation and current velocities, desired track of the drilling platform, and length of the hang-off drilling riser on drilling riser deformation are analysed. This dynamic analysis model focuses on riser strength and deformation of the riser is large, whereas vortex-induced vibration (VIV) lays emphasis on riser fatigue. So VIV is not included in this study.

\section{Analysis model}

Drilling risers generally adopt a soft hang-off mode given the deep water and enormous wave loads in South China Sea $^{15}$. Under soft hang-off mode, the drilling riser with LMRP disconnects from the BOP, and the riser is suspended by the tensioner. The tensioner and telescopic joint bear the weight of the drilling riser. Figure 1 is a schematic for the soft hang-off riser mode. The desired track of the drilling platform may be different from the

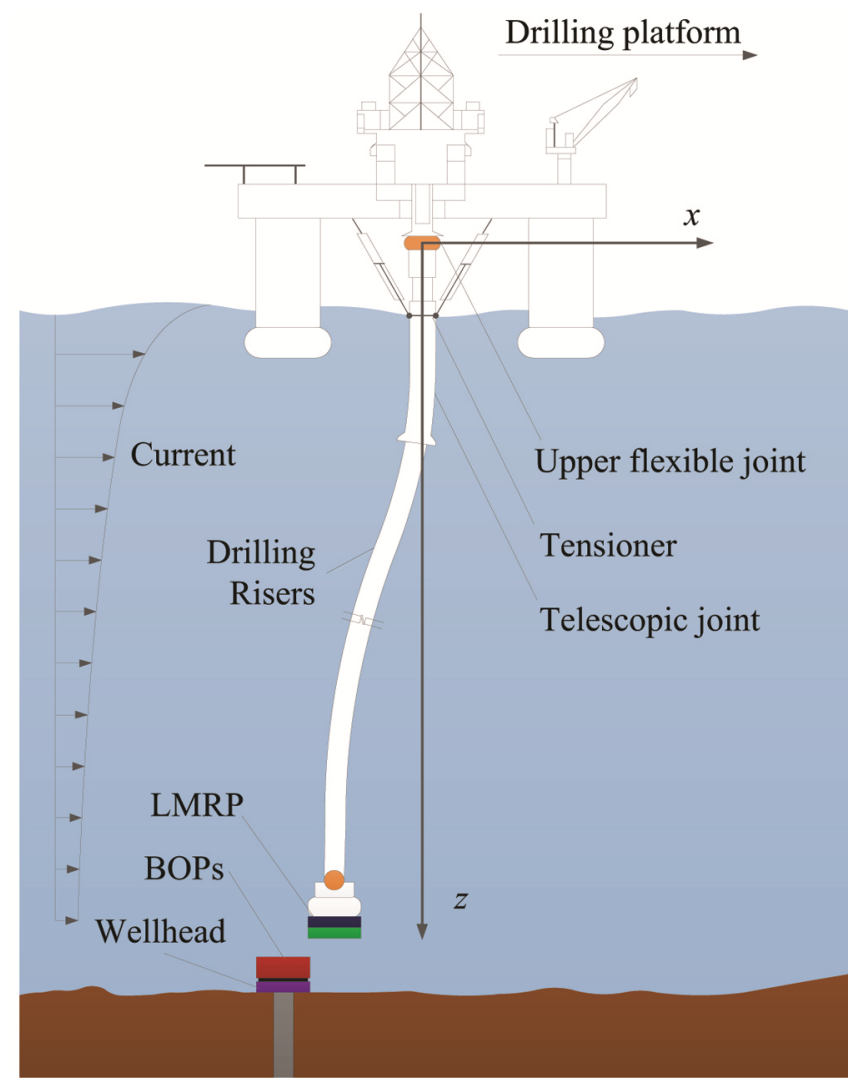

Figure 1. Schematic for soft hang-off mode of a drilling riser. direction of the ocean environment. The riser could be regarded as a cantilever beam with the upper end hinged by the platform and another end free. Figure 2 is a schematic of evacuation for a platform. The movement of the riser can be regarded as a process, coupling the vibration of lateral and longitudinal directions.

\section{Basic assumptions}

In this analysis model, thickness of the riser is constant along the $z$-axis, and the material is presumed homogeneous and isotropic. The variation of string configuration along the longitudinal direction is ignored. After the riser is disconnected from the BOP, the internal fluid and external sea water are connected to each other. Thus, the

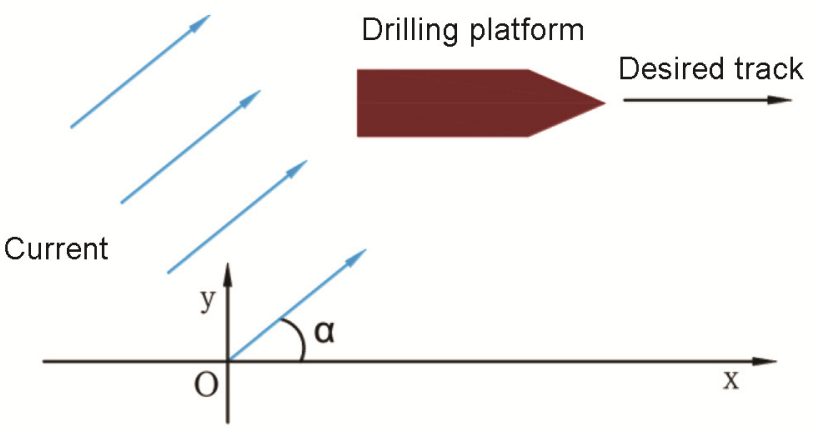

Figure 2. Schematic of evacuation.

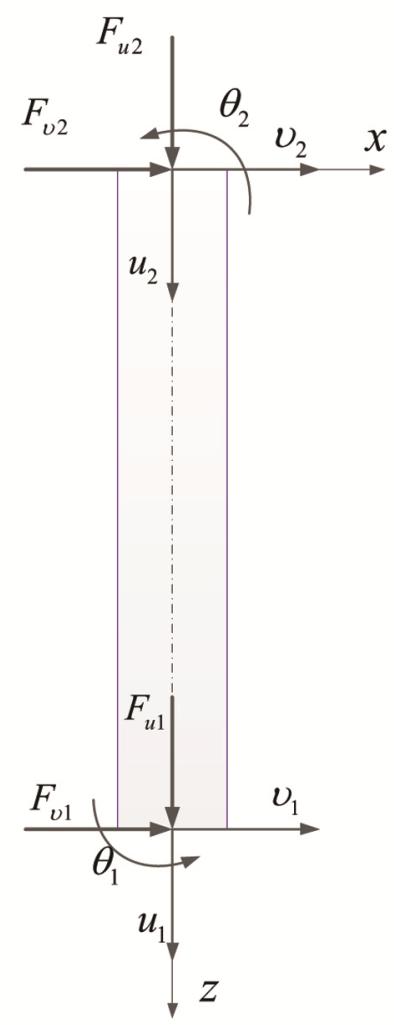

Figure 3. Schematic of force and displacement.

CURRENT SCIENCE, VOL. 116, NO. 9, 10 MAY 2019 
effect of the internal fluid is not considered in the analysis model ${ }^{2,5,7}$. Since the displacement is much larger than the diameter of the riser during evacuation, the damping on the riser is neglected. The length of the riser is considerably larger than its diameter. Hence, the riser could be regarded as an integrated slender cylinder beam and the bending of the joint that connects two single risers is neglected $^{16}$.

\section{Riser model and governing equation}

The drilling riser is a beam with hinges at the upper ends; thus, movement of riser could be described by the governing equation of vibration of the suspension beam in terms of material strength. The entire riser is divided into infinitesimal elements. The movement of each element subjected to forces from the $x$ - and $z$-axes can be described by lateral velocity $u$, longitudinal velocity $v$, and deflection $\theta$. Figure 3 is a schematic of forces and movement. According to Hamilton theory, by coupling the lateral and longitudinal movements, the differential governing equation for the riser can be represented as ${ }^{17}$

$$
\left\{\begin{array}{l}
\rho A \frac{\mathrm{d}^{2} u}{\mathrm{~d} t^{2}}-E A \frac{\partial^{2} u}{\partial z^{2}}=F_{\mathrm{u}}+\xi E A \frac{\partial v}{\partial z} \cdot \frac{\partial^{2} v}{\partial z^{2}} \\
\rho A v+E I \frac{\partial^{4} v}{\partial z^{4}}+\rho I \frac{\partial^{2}}{\partial t^{2}}\left(\frac{\partial^{2} v}{\partial z^{2}}\right)=F_{\mathrm{v}} \\
+E A\left[\xi\left(\frac{\partial^{2} u}{\partial z^{2}} \cdot \frac{\partial v}{\partial z}+\frac{\partial u}{\partial z} \cdot \frac{\partial^{2} v}{\partial z^{2}}\right)+\frac{3}{2} \xi^{2}\left(\frac{\partial v}{\partial z}\right)^{2} \frac{\partial^{2} v}{\partial z^{2}}\right]
\end{array}\right.
$$

where $\rho$ is the material density $\left(\mathrm{g} / \mathrm{cm}^{3}\right), A$ the crosssectional area $\left(\mathrm{m}^{3}\right), t$ the time $(\mathrm{s}), u$ the riser axial deflection $(\mathrm{m} / \mathrm{s}), v$ the riser transverse deflection $(\mathrm{m} / \mathrm{s})$ and $E$ is the Young's modulus $(\mathrm{Pa}) . F_{u}$ the axial direction force distribution along the $z$-axis $(\mathrm{N}), \xi$ denotes the coupling factor that is equal to 1 in the nonlinear system, $I$ the area moment $(N)$, and $F_{v}$ is the lateral force $(N)$.

\section{Boundary conditions}

The drilling riser is a beam hinged by a tensioner. Hence, the riser moving with the platform along the $x$-axis direction and the top end of riser would rate in a specific angle, the rotation stiffness of the upper flexible joint (UFJ) is $K_{\mathrm{u}}$. The upper boundary conditions can be expressed as

$$
\left\{\begin{array}{l}
u(0, t)=u_{\text {boat }}(t) \\
v(0, t)=0 \\
K_{\mathrm{u}} \frac{\partial v}{\partial z}+E I \frac{\partial^{2} v}{\partial z^{2}}=0
\end{array},\right.
$$

where $u_{\text {boat }}$ is the speed of the platform $(\mathrm{m} / \mathrm{s})$ and $K_{u}$ is the rotation stiffness of the UFJ $(\mathrm{Nm} / \mathrm{deg})$.

The other end of the riser is free from any restraint. However, the bottom of the riser must bear the weight of the LMRP. Thus, the lower boundary conditions can be expressed as follows

$$
\left\{\begin{array}{l}
E A\left(\frac{\partial u}{\partial z}+\frac{\xi}{2}\left(\frac{\partial v}{\partial z}\right)^{2}\right)+M_{\text {LMRP }} \frac{\mathrm{d}^{2} u}{\mathrm{~d} t^{2}}=0, \\
\frac{\partial}{\partial z}\left(E I \frac{\partial^{2} v}{\partial z^{2}}\right)-\rho I \frac{\partial}{\partial z}\left(\frac{\mathrm{d}^{2} v}{\mathrm{~d} t^{2}}\right)- \\
E A\left(\xi \frac{\partial u}{\partial z}+\frac{\xi^{2}}{2}\left(\frac{\partial v}{\partial z}\right)^{2}\right) \frac{\partial v}{\partial z}-M_{\text {LMRP }} \frac{\mathrm{d}^{2} v}{\mathrm{~d} t^{2}}=0, \\
E I \frac{\partial^{2} v}{\partial z^{2}}=0
\end{array}\right.
$$

where $M_{\mathrm{LMRP}}$ is the mass of the LMRP $(\mathrm{kg})$.

\section{Ocean environment loads}

The loads applied to the riser comprise the weight of the LMRP, weight of the risers and ocean environment loads. The risers are slender cylinders. Thus, the main ocean environment loads can be simulated by the Morison equation. The cylinder moves with the loads and the displacement of the platform. Therefore, the ocean environmental loads can be calculated as ${ }^{18,19}$

$$
\begin{aligned}
& f_{\mathrm{w}}=\frac{1}{2} C_{\mathrm{D}} \rho_{\mathrm{w}} D\left(v_{\mathrm{w}}-\frac{\mathrm{d} x}{\mathrm{~d} t}\right)\left|\left(v_{\mathrm{w}}-\frac{\mathrm{d} x}{\mathrm{~d} t}\right)\right| \\
& +C_{\mathrm{M}} \rho_{\mathrm{w}} \frac{\pi D^{2}}{4} \frac{\mathrm{d} v_{\mathrm{w}}}{\mathrm{d} t}-C_{\mathrm{m}} \rho_{\mathrm{w}} \frac{\pi D^{2}}{4} \frac{\mathrm{d} v_{\mathrm{w}}}{\mathrm{d} t} \frac{\mathrm{d}^{2} x}{\mathrm{~d} t^{2}},
\end{aligned}
$$

where $C_{\mathrm{D}}$ is the drag force coefficient, $\rho_{w}$ the density of sea water $\left(\mathrm{kg} / \mathrm{m}^{3}\right), D$ the outer diameter of the riser $(\mathrm{m})$, $v_{w}$ the horizontal velocity of the wave water $(\mathrm{m} / \mathrm{s}), x$ the displacement of the riser $(\mathrm{m}), \mathrm{d} x / \mathrm{d} t$ the horizontal velocity of the riser caused by loads and boat movement, $C_{\mathrm{m}}$ the added mass coefficient and $C_{\mathrm{M}}$ is the inertia force coefficient which can be calculated as $C_{\mathrm{m}}+1$.

\section{Solution of the model}

FEM and Newmark- $\beta$ method were used to dissolve the differential governing equation (eq. (1)) of the riser. The Lagrange function and Hermite interpolation method indicate that the finite element formula of the longitudinal 
displacement $u$ and lateral displacement $v$ can be represented as ${ }^{17,20}$

$$
\begin{aligned}
& \left\{\begin{array}{l}
u=\psi^{T} d \\
v=\phi^{T} d
\end{array},\right. \\
& d=\left[\begin{array}{llllll}
u_{1} & v_{1} & \frac{\mathrm{d} v_{1}}{\mathrm{~d} x} & u_{2} & v_{2} & \frac{\mathrm{d} v_{2}}{\mathrm{~d} x}
\end{array}\right]^{T}, \\
& \psi=\left[\begin{array}{llllll}
1-\frac{x}{l} & 0 & 0 & \frac{x}{l} & 0 & 0
\end{array}\right]^{T}, \\
& \varphi=\left[\begin{array}{llllll}
0 & \varphi_{1} & \varphi_{2} & 0 & \varphi_{3} & \varphi_{4}
\end{array}\right]^{T}, \\
& \left\{\begin{array}{l}
\varphi_{1}=1-\frac{3 x^{2}}{l}+\frac{2 x^{3}}{l}, \\
\varphi_{2}=x-\frac{2 x^{2}}{l}+\frac{x^{3}}{l^{2}}, \\
\varphi_{3}=\frac{3 x^{2}}{l^{2}}-\frac{2 x^{3}}{l^{3}}, \\
\varphi_{4}=-\frac{x^{2}}{l}+\frac{x^{3}}{l^{2}},
\end{array}\right.
\end{aligned}
$$

where $l$ is the length of one element.

The element mass matrix $[M]^{e}$ can be determined by

$$
[M]^{e}=\int_{0}^{l} \rho A \psi \psi^{T} \mathrm{~d} x+\int_{0}^{l}\left(\rho A \varphi^{\prime} \varphi^{\prime T}+\rho I \varphi^{\prime} \varphi^{\prime T}\right) \mathrm{d} x .
$$

The element stiffness matrix can be described as

$$
\begin{aligned}
& {[K]^{e}=K_{1}+K_{2}+K_{3}+K_{3}^{T}+K_{4},} \\
& K_{1}=\int_{0}^{l} E A \psi^{\prime} \psi^{\prime T} \mathrm{~d} x, \\
& K_{2}=\frac{1}{4} \xi^{2} \int_{0}^{l} E A \varphi^{\prime} \varphi^{\prime T} v v^{T} \psi^{\prime} \psi^{\prime T} \mathrm{~d} x, \\
& K_{3}=\frac{1}{2} \xi \int_{0}^{l} E A \varphi^{\prime} \varphi^{\prime T} v^{T} \psi^{\prime} \mathrm{d} x, \\
& K_{4}=\int_{0}^{l} E I \varphi^{\prime \prime} \varphi^{\prime \prime T} \mathrm{~d} x,
\end{aligned}
$$

The governing equation can be represented as

$$
[M]\left\{u^{\prime \prime}\right\}+[K]\{u\}=F(t)
$$

where $[M]=T[M]^{e},[K]=T[K]^{e} ;[M]$ is the global mass matrix, $[K]$ the global stiffness matrix and $T$ is the transformation matrix for transforming partial coordinates to global coordinates.
Equation (13) can be solved by the Newmark- $\beta$ method (see Mao et al. ${ }^{2}$ ).

\section{Validity of the analysis model}

Liu et $a l .{ }^{14}$ simulated a hang-off riser using ABAQUS software with marine engineering module ABAQUS/aqua and presented the distribution of horizontal displacement in $12 \mathrm{~s}$. For thorough comparison, we have calculated the maximum deformation of riser with the basic parameters of literature ${ }^{14}$. As shown in Figure 4, the result of our analysis model is in good agreement with that of ABAQUS, which indicates the accuracy of our model.

To further verify the accuracy of the numerical model we conducted an experiment in Southwest Petroleum University (Chengdu, Sichuan, China). Figure 5 shows photographs of the experimental circular cistern. The experimental marine riser is made of $\mathrm{PE}$ that can rotate around the centre of the circular cistern. Table 1 lists the major properties of the riser and basic parameters of the calculation model.

We regard uniform flow, which is generated by the movement of the riser, as the ocean current load in this experiment to stimulate the environmental loads. Strain gauges were attached to the surface of the riser to collect deformation data (Figure 6). To guarantee the accuracy of the stimulated result, we can eliminate the influence of VIV on the deformation of the riser using a mean value treatment in the longitudinal direction. Figure 7 presents a comparison of the numerical and experimental results. The actual shear flow is assumed as uniform, and the upper part of riser is fixed due to the limit of the water depth in this experiment, thereby resulting in differences of deformation between the numerical and experimental data. Even though it is hard to conduct an experiment integrity considering the ocean condition, the result could still primly prove the correctness of our numerical model.

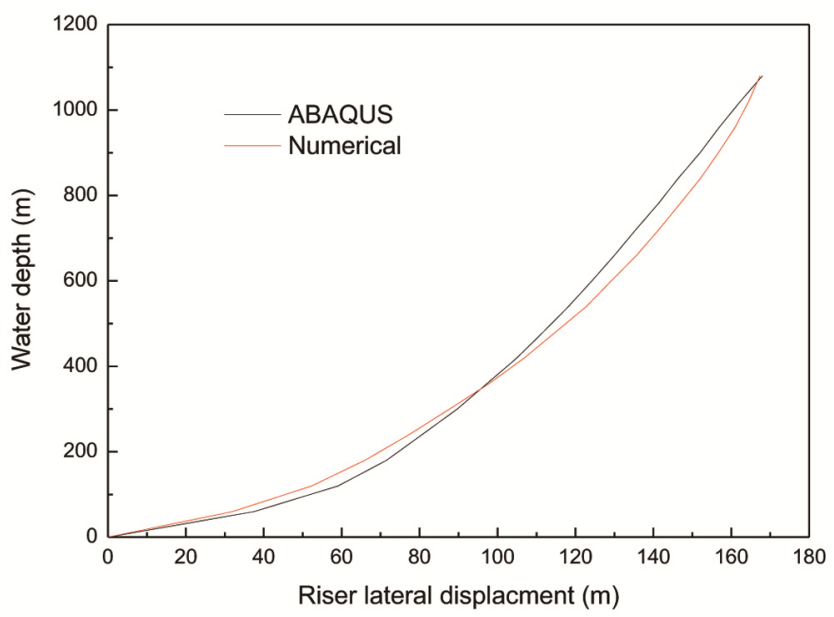

Figure 4. Comparison of the numerical and ABAQUS results. 


\section{Applications and case study}

\section{Riser model analysis}

The dynamic response characteristics of the riser in a deep-water well in South China Sea were analysed. Table 2 provides the main properties of the riser system ${ }^{2}$ while

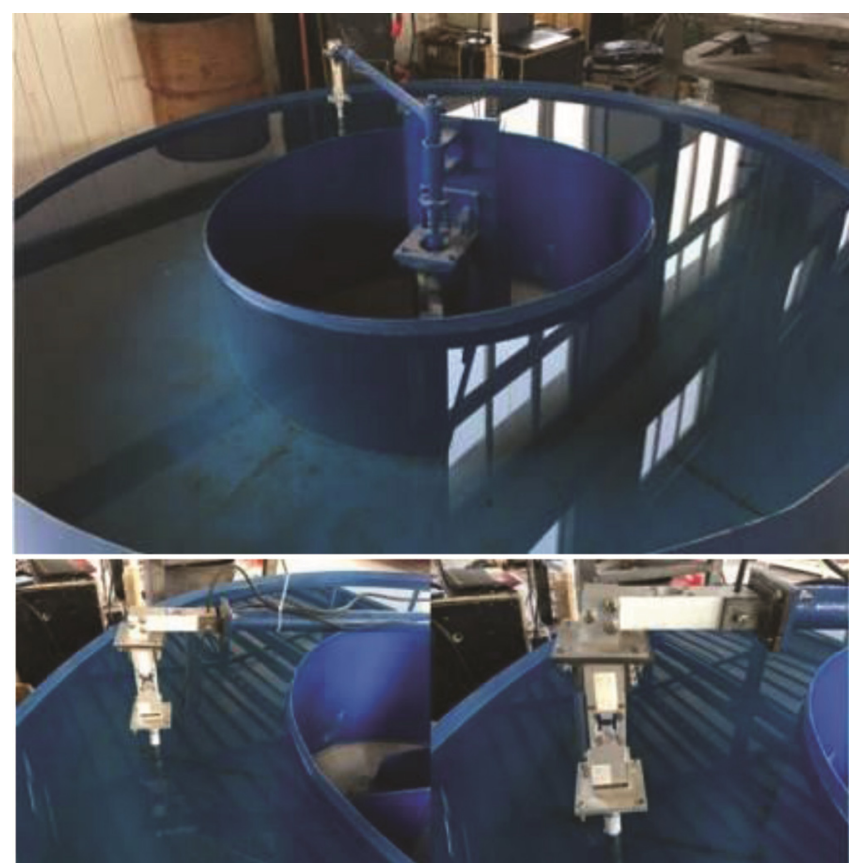

Figure 5. Photographs of the drilling riser.

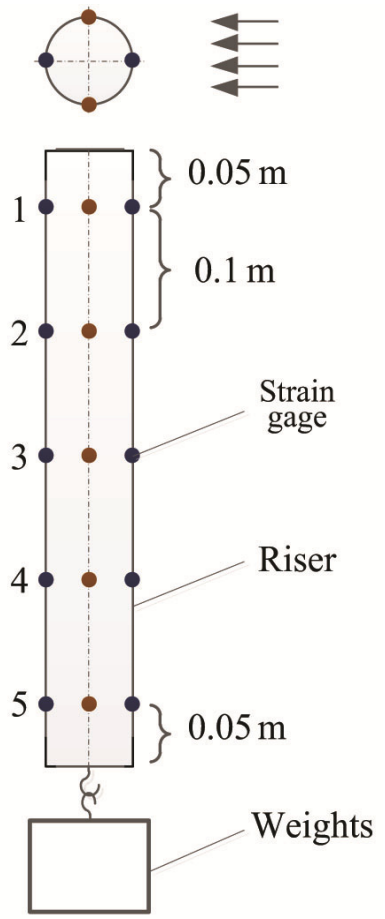

Figure 6. Arrangement of the strain gauge.
Table 3 lists the hydrodynamic properties in South China $\mathrm{Sea}^{2,21,22}$. Figure 8 shows the distribution of surface current speed in South China Sea ${ }^{15}$.

The model was analysed using FEM, for which the riser was divided into 50 elements of equal length. The time step was set as $0.00163 \mathrm{~s}$, and the calculated results varied with time. Moreover, we focused on the major factors of deformation, bending moment and longitudinal vibration. In this analysis model, the upper section of the riser moves with the platform in a specific speed while the water flows. Figure 2 shows the relationship of direction between the platform and the current flow. Thus, the relative velocity of the platform and surface current were calculated as the ocean environmental load. Then, the position of the platform was set as the origin point of the coordinates in the calculation.

Figure $9 a$ presents the lateral displacement along the axial direction of the riser at $130 \mathrm{~s}$. The lateral displacement increases rapidly with increase in water depth, with maximum displacement of $58.2 \mathrm{~m}$ at the LMRP site. However, the lateral displacement close to LMRP

Table 1. Main physical properties of the drilling riser model

\begin{tabular}{lc}
\hline Item & Value \\
\hline Model length $(\mathrm{m})$ & 0.5 \\
Thickness $(\mathrm{m})$ & 0.001 \\
Outer diameter $(\mathrm{m})$ & 0.0065 \\
Density $\left(\mathrm{kg} / \mathrm{m}^{3}\right)$ & 950 \\
Young's modulus $(\mathrm{GPa})$ & 0.8 \\
Density of basin water $\left(\mathrm{kg} / \mathrm{m}^{3}\right)$ & 1000 \\
\hline
\end{tabular}

Table 2. Main properties of the riser system

\begin{tabular}{lc}
\hline Property & Value \\
\hline Outer diameter of riser $(\mathrm{m})$ & 0.5334 \\
Wet weight of a single bare riser $(\mathrm{kg})$ & 439 \\
Density of the riser material $\left(\mathrm{kg} / \mathrm{m}^{3}\right)$ & 7850 \\
Modulus of elasticity $(\mathrm{GPa})$ & 210 \\
Total length of the riser $(\mathrm{m})$ & 1800 \\
Density of seawater $\left(\mathrm{kg} / \mathrm{m}^{3}\right)$ & 1025 \\
LMRP mass $(\mathrm{kg})$ & 140,000 \\
Length of a single riser $(\mathrm{m})$ & 23.7 \\
Rotational stiffness of the upper flex joint $(\mathrm{N} . \mathrm{m} / \mathrm{deg})$ & 8800 \\
Platform velocity $(\mathrm{m} / \mathrm{s})$ & 1 \\
Flow velocity $(\mathrm{m} / \mathrm{s})$ & 1 \\
\hline
\end{tabular}

Table 3. Hydrodynamic properties in South China Sea

\begin{tabular}{lcc}
\hline Property & \multicolumn{1}{c}{ Value } & Unit \\
\hline Drag coefficient, $C_{\mathrm{D}}$ & $\begin{array}{c}1.2 \text { (between the water surface } \\
\text { and } 150 \mathrm{~m} \text { depth) } \\
0.7 \text { (between } 150 \mathrm{~m} \text { and the }\end{array}$ & Zero dimension \\
& seabed) & \\
Inertia coefficient, $C_{\mathrm{m}}$ & 2.0 (at all depths) & Zero dimension
\end{tabular}


increases gradually; the riser in this part is vertical. The weight of the LMRP is considerably larger than that of a single riser; thus, a heavier object has larger inertia, which is the force that keeps the object in its original position until it moves ${ }^{9}$.

Figure $9 b$ shows the bending moment along the axial direction of the riser at $130 \mathrm{~s}$. The bending moment near the UFJ is large, and the maximum bending moment of $52 \mathrm{KN} \cdot \mathrm{m}$ is located near the water surface. The bending moments at other positions of the riser are small but unstable since the movement of the riser is a dynamic process, and the bending moment only reflects the relative degree of deformation in one moment. The surface of water is the boundary of the loads and also where they reach a high point ${ }^{2,15}$. Thus, deformation increases suddenly, the curve of the lateral displacement is rough near the water surface, and the value of the bending moment is large.

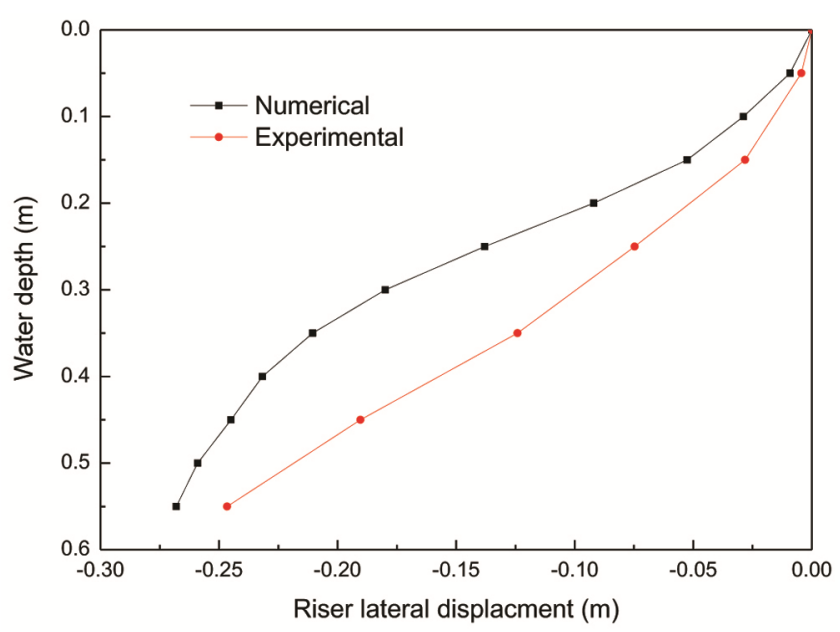

Figure 7. Comparison of the numerical and experimental results.

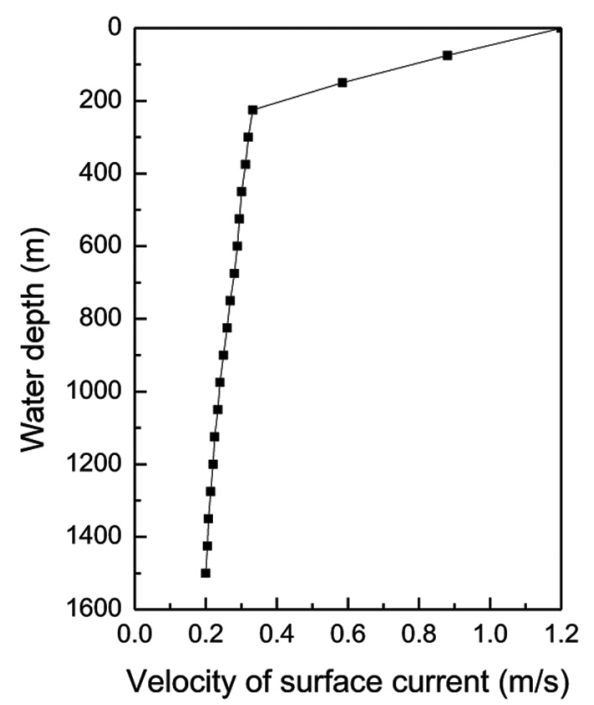

Figure 8. Distribution of surface current speed.
Figure $9 c$ shows changes in the lateral displacement along the axial direction of the riser at 10, 40, 70, 100, and $130 \mathrm{~s}$. The figure vividly presents the dynamic variation of the riser with time. At $10 \mathrm{~s}$, as the riser starts moving deformation is small. As time progresses, the deformation increases smoothly. The lower segments of the riser consistently have a larger deformation than the upper segments; maximum displacement is constantly located near the LMRP. In this study, the riser is regarded as a soft beam restrained at the upper end, which is subjected to the law of deformation of a suspended beam ${ }^{17}$. The other end of the riser is free from any restrain, and its deformation is the largest in our model.

Figure $9 d$ shows the longitudinal vibration responses of the riser at locations of 0,1000 and $1500 \mathrm{~m}$. The frequency of the vibration curve is consistent at all positions. However, the amplitude evidently increases with water depth. The initial sinusoidal vibration is applied on the platform, according to our hypothesis; thus, the response of the longitudinal vibration at $0 \mathrm{~m}$ is a standard sinusoidal wave. At depths of 1000 and $1500 \mathrm{~m}$, floor level of the amplitude increases compared with that of the initial sinusoidal wave. At the incipient stage, the longitudinal deformation of the riser is small. The floor level of the amplitude at this stage is lower than that of the initial sinusoidal wave. However, at the subsequent stage, the entire response of the riser increases with the loads. Stretching the riser causes the level of the curve to clamp gradually.

\section{Influence of LMRP weight on riser mechanical behaviour}

Figure 10 shows the distribution of the riser lateral displacement, bending moment and longitudinal vibration for the deep-water well under LMRP weight change from 140 to 120 tonnes. The LMRP can be regarded as a massy plummet connected to the lower end of riser under hangoff condition, and it moves with the riser motion. Figure $10 a$ shows that lateral displacement of the riser increases from top to bottom and reaches a maximum at the bottom end. The lateral displacement of the riser increases with increase in LMRP weight from 140 to 120 tonnes. Thus, maximum displacement of $62.7 \mathrm{~m}$ is reached at the lower end with the LMRP weight of 120 tonnes. Figure $10 b$ shows that the bending moment of the riser decreases with increase in LMRP weight. Moreover, maximum bending moment occurs at a position close to the upper end. Figure 8 shows the distribution of ocean environmental loads. The loads applied onto LMRP are considerably smaller than those close to the upper end. The upper part consistently moves faster than the lower part because the movement of the riser is stimulated by the loads and platform movement. Thus, the riser is an oblique state. The component force of the weight drags the riser to 

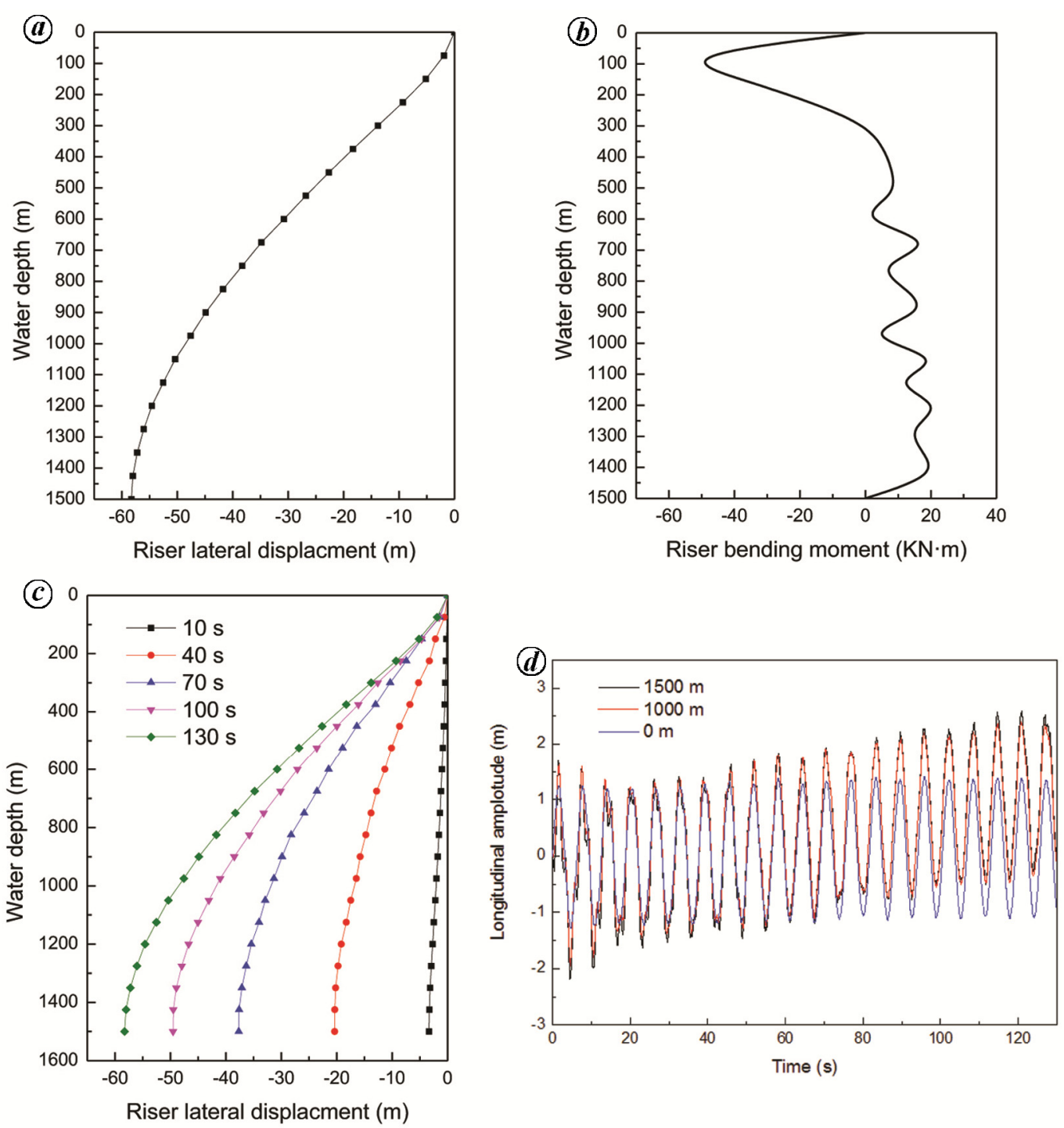

Figure 9. Hang-off riser mechanical behaviour of the deep-water well in South China Sea under the calculated ocean environment: $(\boldsymbol{a}-\boldsymbol{d})$ Distributions of the riser lateral displacement, bending moment, dynamic lateral displacement from the upper flex joint to the seabed, and longitudinal vibration at the bottom respectively.
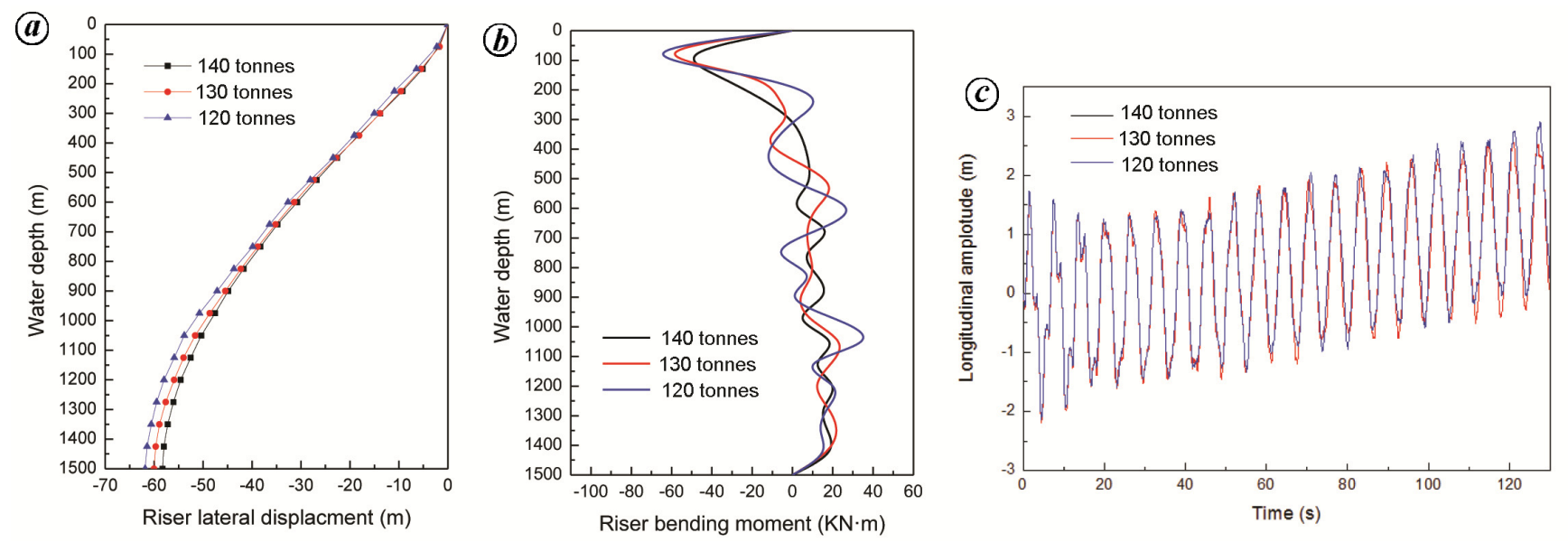

Figure 10. Hang-off riser mechanical behaviour with LMRP weight of 140, 130, and 120 tonnes. $\boldsymbol{a}-\boldsymbol{c}$, Distributions of the riser lateral displacement, bending moment from the upper flex joint to the seabed, and longitudinal vibration at the bottom respectively. 

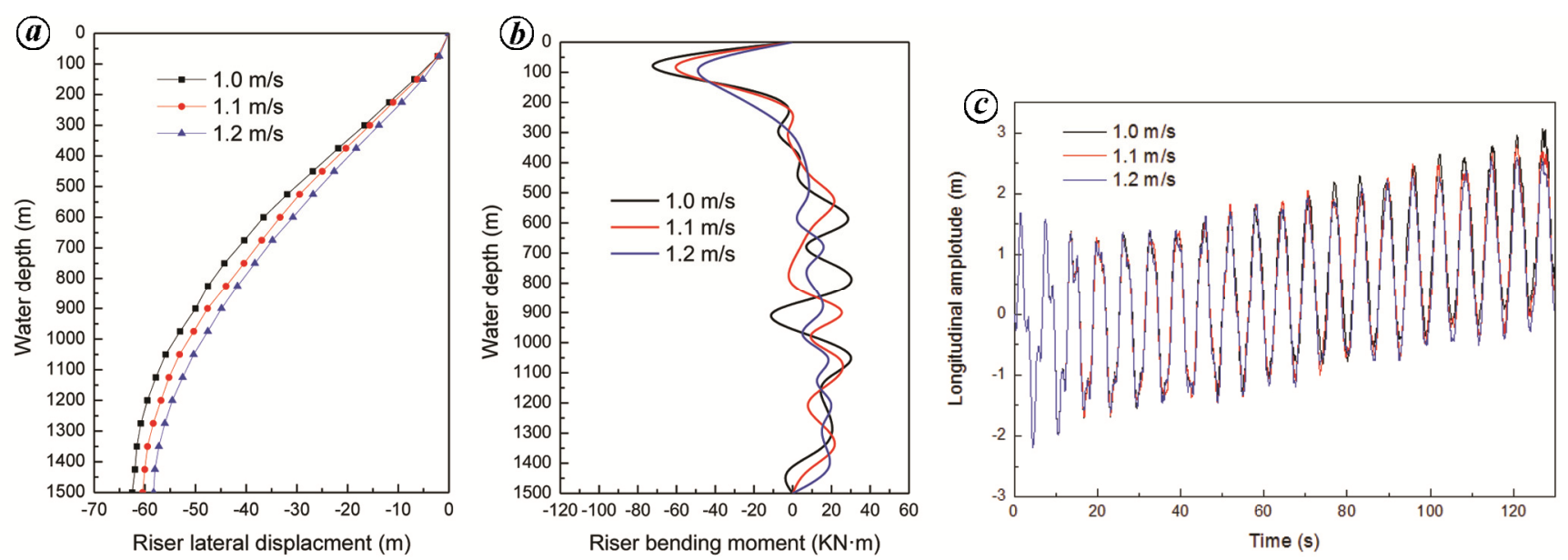

Figure 11. Hang-off riser mechanical behaviour with surface current speed of $1.0,1.1$ and $1.2 \mathrm{~m} / \mathrm{s}$. $\boldsymbol{a}-\boldsymbol{c}$, Distribution of the riser lateral displacement, bending moment from the upper flex joint to the seabed, and longitudinal vibration at the bottom, respectively.

become vertical, and a heavy LMRP makes it difficult for the riser to move. Meanwhile, a heavier LMRP indicates a larger inertia, thereby damping the movement of the riser in deep water ${ }^{9}$. Figure $10 c$ shows that the longitudinal vibration of the lower end of the riser decreases with increase in LMRP weight during the entire evacuation process. All four curves have similar sinusoidal wave and trend. However, the amplitude is large when LMRP is not heavy. As shown in Figure $10 a$, the largest lateral displacement occurs for 120 tonnes. Thus, LMRP weight is an obstruction to the movement of the riser. Therefore, the riser with a weight of 120 tonnes is clearly stretched, and the extent of the vibration is large. Thus, a heavy LMRP is beneficial to reduce the deformation of the riser and protect it during the evacuation process. Therefore, the platform with a heavier LMRP could evacuate at a large velocity to keep the riser safe ${ }^{23}$.

\section{Influence of surface current speed on riser mechanical behaviour}

Figure $11 a-c$ shows distribution of the riser lateral displacement, bending moment and longitudinal vibration with surface current speeds of $1.0,1.1$ and $1.2 \mathrm{~m} / \mathrm{s}$ respectively. The riser lateral displacement and bending moment decrease with increase in fluid velocity. In this case, the platform velocity is $1.289 \mathrm{~m} / \mathrm{s}$, which is larger than the surface current velocity. The relative speed between water and the platform decreases with increase in fluid speed, thereby inducing a decrease in environmental loads and deformation of the riser. Morison's equation implies that the environment is directly proportional to the difference in speed between the surface current and the platform ${ }^{18}$. Moreover, as the surface current speed increases, amplitude of vibration decreases with increase in lateral displacement. However, the frequency and trend of the curve remain similar. Thus, a small relative speed between water and the platform is advantageous to reduce the deformation of the riser $^{5,6}$.

\section{Influence of platform speed on riser mechanical behaviour}

Figure $12 a-c$ shows distribution of the riser lateral displacement, bending moment and longitudinal vibration with platform speeds of $2.4,2.5$ and $2.6 \mathrm{kn}$ respectively. The lateral displacement, lotuding moment and longitudinal vibration of riser increase as the current speed increases. In this case, the velocity of surface current is $1.2 \mathrm{~m} / \mathrm{s}$, which is smaller than the smallest platform velocity of $2.4 \mathrm{kn}(1.23 \mathrm{~m} / \mathrm{s})$. Thus, the relative speed between water and the platform decreases with increase in surface current speed. Figure 8 shows the distribution of the environmental loads, which indicates that the environmental loads applied to the riser increase with the velocity of surface current, thereby weakening the dynamic vibration process while the weight of the riser is unchanged $^{5,6}$. Therefore, change in vibration amplitude with the increase in surface current speed is small (Figure $12 \mathrm{c}$ ). Consequently, maintaining a platform speed close to the surface current is a suitable approach to protect the riser during evacuation.

\section{Influence of the desired track of drilling platform on riser mechanical behaviour}

Figure $13 a-c$ shows the influence of the desired track of the drilling platform on the distribution of the riser lateral displacement, bending moment and longitudinal vibration respectively. The velocity of the surface is larger than that of the platform; Figure 2 shows the track disposal of the platform. As the relative speed between the platform and surface current decreases, lateral displacement 

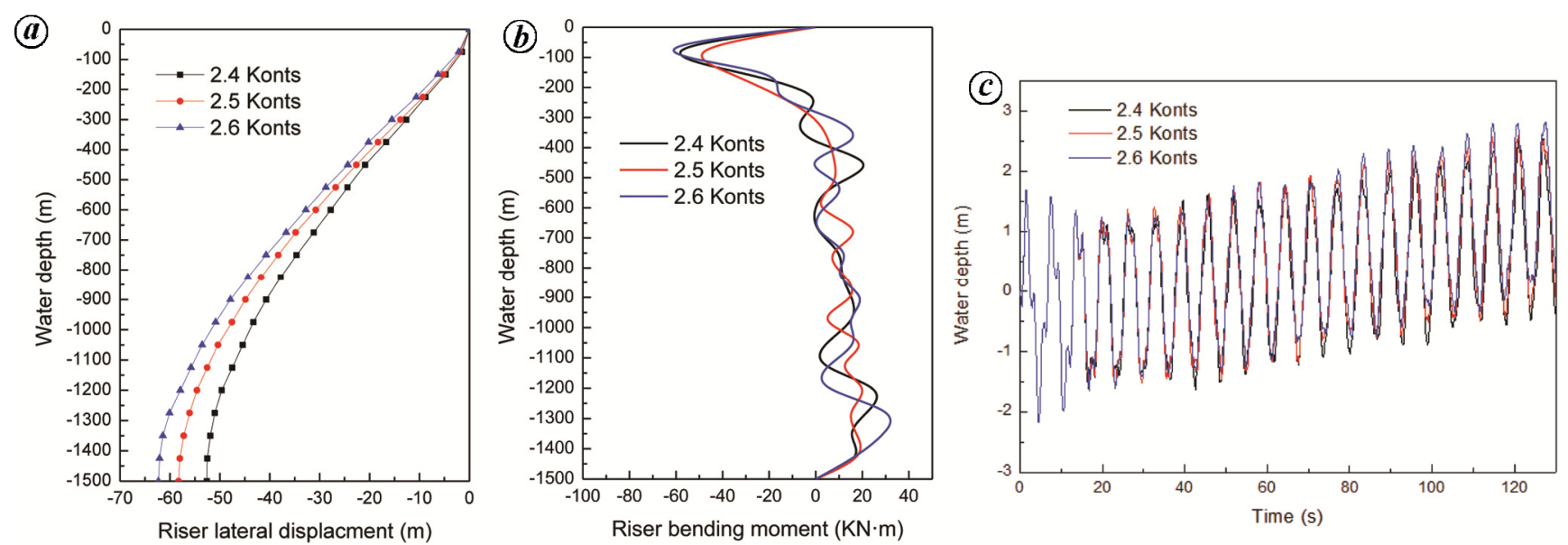

Figure 12. Hang-off riser mechanical behaviour with platform speed of $2.4,2.5$ and $2.6 \mathrm{kn}$. $\boldsymbol{a}-\boldsymbol{c}$, Distribution of the riser lateral displacement, bending moment from the upper flex joint to the seabed, and longitudinal vibration at the bottom respectively.

decreases with increase in angle between the platform evacuation direction and current direction. When the angle is $90^{\circ}$, relative speed is equal to the platform speed. There, the deformation direction of riser with an angle of $90^{\circ}$ is contrary to that of $0^{\circ}$ and $45^{\circ}$. When the angle is $0^{\circ}$, the directions of the velocity of the platform and surface current are the same, and relative speed reaches a high point. The deformation and amplitude of riser with the angle are considerably larger than that of $45^{\circ}$ and $90^{\circ}$. Angles larger than $90^{\circ}$ are not discussed here because they increase the relative speed, which increases the deformation of the riser. Consequently, when the surface current speed is considerably larger than that of the platform, driving the platform against the surface current direction during evacuation is dangerous ${ }^{23}$.

\section{Influence of suspension length on riser mechanical behaviour}

Figure $14 a-c$ shows the influence of suspension length on the distribution of lateral displacement, bending moment and longitudinal vibration of the riser respectively. The lateral displacement and bending moment of the riser increase with the length of the riser. Figure $14 c$ shows that the amplitude of the vibration curve increases with the suspension length. When the riser is short $(1200 \mathrm{~m})$, its entire weight and flexibility are also small. The movement of the riser directly reflects the stress response of the environmental loads and platform movement. Meanwhile, the environmental load of the surface current is considerably larger at the water surface (Figure 11). A short riser moves easily with the affecting of the current motion, whereas a long and heavy riser does not respond because rigid bodies stop its movement but exhibit axial stretch and contraction, thereby magnifying the tension excursions of the riser. The movement of a long riser is an elastic response under the environment and self-weight loads ${ }^{10}$. Therefore, a short riser is beneficial to reduce the deformation of the entire riser, but is harmful to the UFJ. Taking back parts of risers to the platform before evacuation could apparently reduce the degree of riser defomation $^{4,5,23}$.

\section{Discussion}

During evacuation condition, the soft hang-off mode riser is likely to generate the largest deformation due to rotational stiffness of the top end. Risers may be easily fractured if the deformation and bending moment surpass their maximum limits. Meanwhile, a large longitudinal vibration may cause grounding accident and damage the LMRP, tensioner and moon pool. Here we provide several operation suggestions during evacuation by analysing the influences on the dynamical mechanic behaviour of the soft hang-off riser.

A heavy LMRP is beneficial to control the movement of the riser and increase the available velocity of the platform, but generally, it is unchangeable in a specific case. Environmental load greatly affects the deformation of the riser. Different combinations of velocity of surface current, velocity of platform and the desired track of the platform influence the environment mainly by changing the relative velocity between water and platform. Therefore, velocity of the platform must be maintained at a low level and the desired track must not be against the direction of the surface current during evacuation, to reduce the deformation of the riser and protect the riser and the $\mathrm{UFJ}^{5,15}$. In addition, taking back parts of risers to the platform is a feasible operation for protecting the riser, because it would not only reduce the weight of the riser and the lateral displacement, but also reduce the longitudinal vibration which could effectively prevent grounding accidents $^{4,5}$. However, unceasingly taking back the riser to reduce its suspension length is discouraged because a 

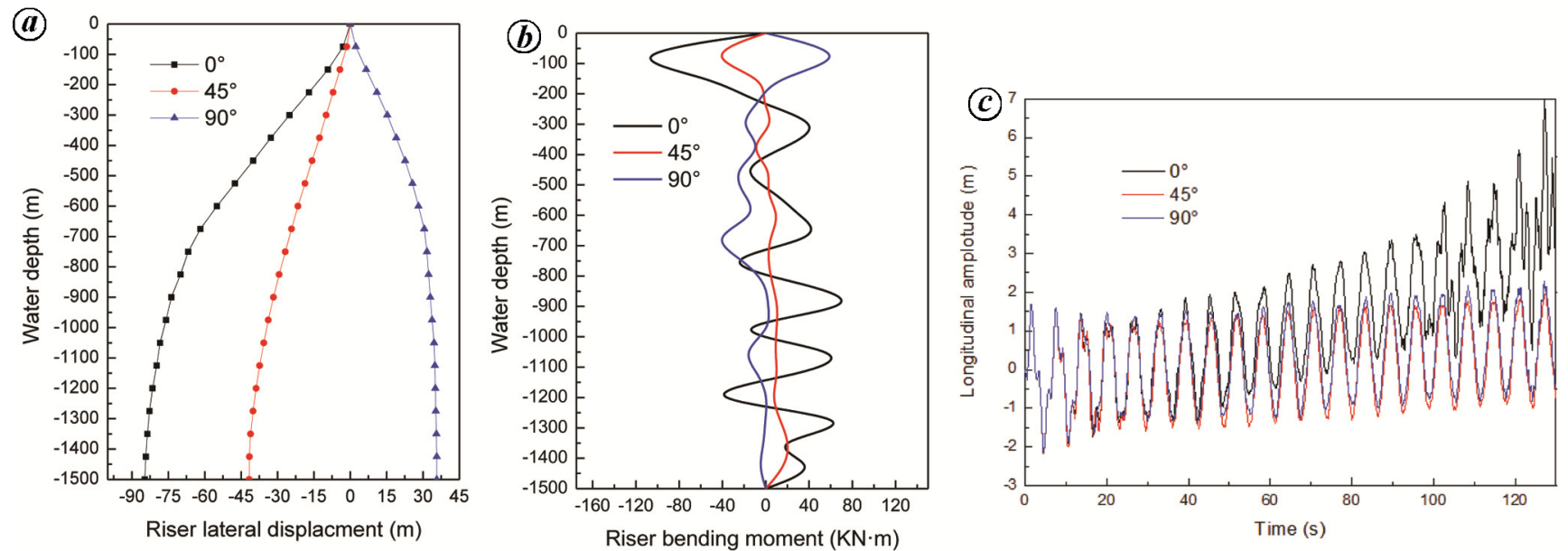

Figure 13. Hang-off riser mechanical behaviour with the desired track of $0^{\circ}, 45^{\circ}$ and $90^{\circ}$. $\boldsymbol{a}-\boldsymbol{c}$, Distribution of the riser lateral displacement, bending moment from the upper flex joint to the seabed, and longitudinal vibration at the bottom respectively.
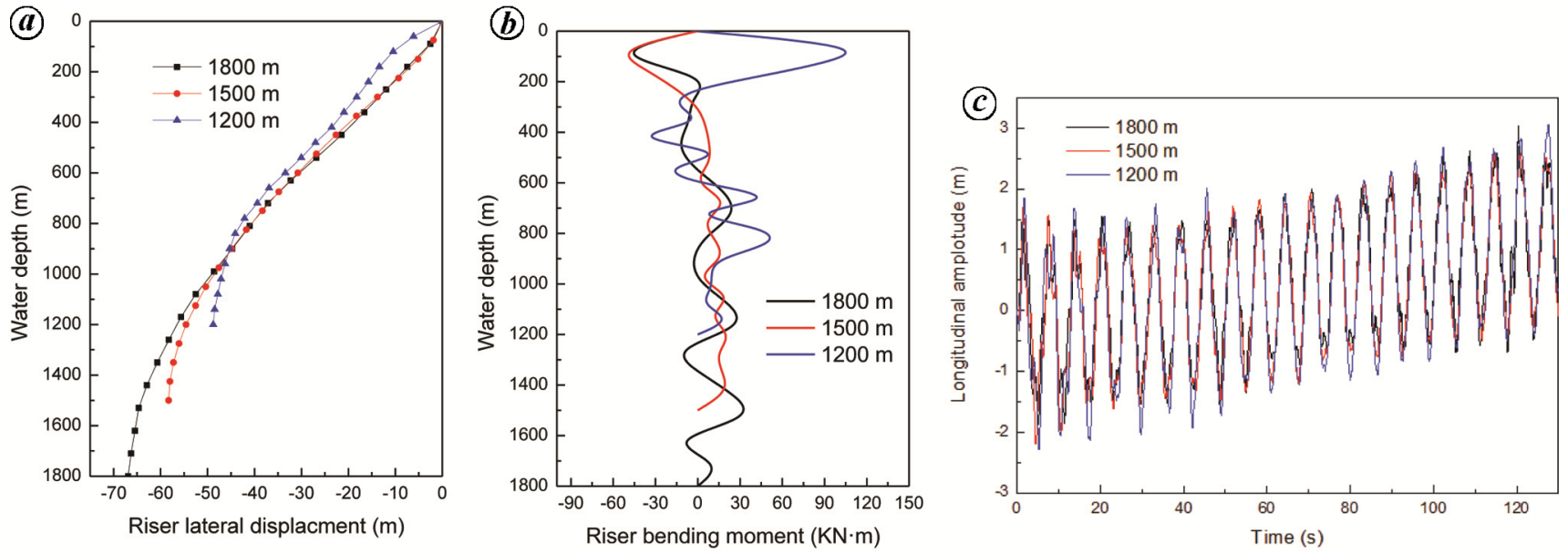

Figure 14. Hang-off riser mechanical behaviour with suspension length of 1200,1500 and $1800 \mathrm{~m}$ : $\boldsymbol{a}-\boldsymbol{c}$, Distribution of the riser lateral displacement, bending moment from the upper flex joint to the seabed, and longitudinal vibration at the bottom respectively.

short suspension riser easily sinks and rises given the direct effect of surface current, thereby damaging the tensioner and telescope joint ${ }^{23}$. Moreover, excessive time while taking back the riser may fail to achieve the best opportunity for safe evacuation.

\section{Conclusion}

The distribution of riser lateral displacement, bending moment and longitudinal vibration decrease with increase in the weight of LMRP; variation of lateral displacement with change in LMRP weight mainly occurs close to LMRP. The velocity of surface current, velocity of platform and the desired track of the platform together determine the relative velocity between surface current and platform. A large relative velocity between surface current and platform will significantly increase the lateral displacement, bending moment and longitudinal vibration of the riser. The length of the riser has an obvious effect on its dynamic behaviour; deformation of the riser increases with increase in riser length. However, variation of riser length will apparently affect the dynamic movement of the riser.

1. Xu, L., Zhou, J., Wang, R., Jiang, S. and Sheng, L., Analysis of deep water drilling platform evacuation from imminent typhoons with riser hang-off in South China Sea. China Offshore Oil and Gas, 2015, 27(3), 101-107.

2. Mao, L., Liu, Q., Zhou, S., Wang, G. and Fu, Q., Deep water drilling riser mechanical behaviour analysis considering actual riser string configuration. J. Nat. Gas Sci. Eng., 2016, 33, 240-254.

3. Fan, H., Li, C., Wang, Z., Xu, L., Wang, Y. and Feng, X., Dynamic analysis of a hang-off drilling riser considering internal solitary wave and vessel motion. J. Nat. Gas Sci. Eng., 2017, 37, 512522 .

4. Steddum, R., The management of long, suspended strings of tubulars from floating drilling vessels. In Offshore Technology Conference, Houston, Texas, 2003. 
5. Sheng, L., Xu, L., Zhou, J., Jiang, S. and Li, X., Experience on deep-water drilling riser about hang-off modes in typhoon condition of South China Sea. In Offshore Technology Conference, Kuala Lumpur, Malaysia, 2016.

6. Wu, W., Wang, J., Tian, Z., Fu, S., Liu, Z. and Luo, J., Dynamical analysis on drilling riser evacuated in hard hang-off mode. In International Ocean and Polar Engineering Conference, Busan, South Korea, 2014.

7. Liu, X., Chen, G., Chang, Y., Fu, J. and Ji, J., Weak point and operation analysis of deep-water drilling riser system in typhoon condition. International Society of Offshore and Polar Engineers, San Francisco, USA, 2017.

8. Wang, Y., Cao, J., Sha, Y., Duan, M., Wang, D., Dong, Y. and Zhou, Y., SCR hang-off system selection considerations and criteria. International Society of Offshore and Polar Engineers, Hawaii, USA, 2011.

9. Ambrose, B. D., Grealish, F. and Whooley, K., Soft hangoff method for drilling risers in ultra deep-water. In Offshore Technology Conference, Houston, Texas, 2001.

10. Long, J. R., Steddum, R. and Young, R. D., Analysis of a 6000-ft riser during installation and storm hangoff. In Offshore Technology Conference, Houston, Texas, 1983.

11. Dai, W., Gao, F. and Bai, Y., FEM analysis of deep-water drilling risers under the operability and hang-off working conditions. $J$. Mar. Sci. Appl., 2009, 8(2), 156-162.

12. Yasukawa, H., Ozaki, M. and Tanabe, A., Tension variation and limiting wave height of a deep sea drilling riser in hang-off mode. J. Jpn Soc. Nav. Archit. Ocean Eng., 2009, 1997(182), 187-198.

13. Burgdorf Jr, O., Evaluation of axial and lateral modal superposition for general $3 \mathrm{~d}$ drilling riser analysis. In Offshore Technology Conference, Houston, Texas, 1996.

14. Liu, X., Chen, G., Chang, Y., Liu, K., Zhang, L. and Xu, L., Analyses and countermeasures of deep-water drilling riser grounding accidents under typhoon conditions. Pet. Exp. Dev., 2013, 40(6), 791-795.
15. Qi, J., A study on structure dynamics and vortex shedding vibration of drilling risers under hang off mode. Shanghai Jiao Tong University, Shanghai, China, 2015.

16. Wang, J., Duan, M., He, T. and Jing, C., Numerical solutions for nonlinear large deformation behaviour of deep-water steel lazywave riser. Ships Offshore Struct., 2014, 9(6), 655-668.

17. Xing, Y. and Liang, K., Nonlinear vibration analysis of longitudinal-transverse coupled beam. J. Beijing Univ. Aeronaut. Astronaut., 2015, 41(8), 1359-1366.

18. Morison, J. R., The force exerted by surface waves on piles. J. Petrol. Technol., 1950, 189(5), 149-154.

19. Han, S. M. and Benaroya, H., Non-linear coupled transverse and axial vibration of a compliant structure, part 1: formulation and free vibration. J. Sound Vibr., 2000, 237(5), 837-873.

20. Liu, J., Zhao, H., Liu, Q., He, Y., Wang, G. and Wang, C., Dynamic behaviour of a deep-water hard suspension riser under emergency evacuation conditions. Ocean Eng., 2018, 150, 138151.

21. Fang, H. C., Dong, S. P., Jin, F. and Xu, X. P., Experiment and study of the drag coefficient for drilling riser. Oil Field Equip., 1987, 15(2), 1-6.

22. Wang, S. Q. and Liang, B. C., Wave Mechanics for Ocean Engineering, Ocean University of China Press, Qindao, China, 2013.

23. Brekke, J., Soles, J., Wishahy, M. and Stahl, M., Drilling riser management for a DP drillship in large, rapidly - Developing sea states in deepwater, Society of Petroleum Engineers, Dallas, Texas, 2004.

ACKNOWLEDGEMENT. We acknowledge financial support from the National Natural Science Foundation of China (No. 51604235), Scientific Research Starting Project of SWPU (No. 2015QHZ007).

Received 5 November 2018; revised accepted 31 December 2018 doi: $10.18520 / \mathrm{cs} / \mathrm{v} 116 / \mathrm{i} 9 / 1533-1543$ 